\title{
PUBLIC REALM AS CITY WELFARE \& CITIZENS WELLBEING: THE CASE OF CAO YANG - SHANGHAI
}

\author{
Maria Chiara TOSI ${ }^{\mathrm{a}}$, Margherita E. TURVANI ${ }^{\mathrm{b}}$, Stefano MUNARIN ${ }^{\mathrm{c}}$ \\ ${ }^{a}$ Department of Architecture and Art, University IUAV of Venice, Dorsoduro 2206, 30123, Venice, Italy \\ ${ }^{b}$ Department of Design and Planning in Complex Environments, University IUAV of Venice, \\ Santa Croce 1957, 30135, Venice, Italy \\ 'Department of Architecture and Art, University IUAV of Venice, Dorsoduro 2206, 30123, Venice, Italy \\ E-mails: ${ }^{2}$ mariachiara.tosi@iuav.it (correspondingauthor); ${ }^{b}$ margheri@iuav.it; ${ }^{c}$ munarin@iuav.it
}

Received 06 October 2016; accepted 08 February 2017

\begin{abstract}
This paper discusses how the improvement of the quality of collective and public spaces can positively affect the wellbeing of the citizens and the welfare of the city, using as a demonstration site Cao Yang New Village, one of the first planned urban development for workers in Shanghai, China, designed and built during the Fifties of the past century, just few years later Mao Zedong proclaimed the establishment of the People's Republic of China, on October 1, 1949.

The paper shows how, by careful design interventions, the enhancement of the connectivity and of the porosity in the neighbourhood gives rise to an easier accessibility for citizens, especially for children, mothers, elderly, and people with disabilities, allowing them to get to schools, parks, sport facilities, public offices and other collective spaces, therefore improving their wellbeing. By detailed and careful design, appropriate urban policies in Chinese cities can help to respond to the citizens increasing demand for public space. Our work suggests that a similar approach should be included in many cities agenda in China, to align to the China's New Urbanization Plan 2014-2020 that focuses on sustainable growth, improved people's living conditions and a clearer cultural identity.
\end{abstract}

Keywords: public space, wellbeing, welfare, connectivity, porosity, accessibility, design.

\section{Introduction}

In the Western world, traditionally, discourses on urban public space extend beyond the mere physical dimensions of urban space and they underpin the essential attribute of "public"; then, every discourse about public space immediately relates to value issues, including social and cultural issues.

The notion of "public" and the notion of "urban space" combined (the term "urban public space") highlights connectedness between the concrete space (phys$\mathrm{ical} /$ architectural/urban space), experienced by people, as the container of urban activities in the everyday life, with the metaphorical (social/political/cultural) space, thus introducing dimensions of social, political and cultural relations and therefore the role of institutions in space.

A multiplicity of meanings attaches to "public", "public space" and the "public sphere", raising a crucial issue, namely the relationship between public space and the public sphere (Low, Smith 2006).

According to Jurghen Habermas, in western countries public sphere arises together with the nascent modernity of the late eighteenth century (Habermas 1989). The seeds of this conception were slowly transplanted in China, where only in the late nineteenth century, with the development of the rail transportation and the introduction of more modern modes of production, the urban life assumed some of the typical western features (Gaubatz 2008).

It is only in the twentieth century, and most likely in the last half of it, that Chinese cities start facing the rising demand for public and collective spaces, to be used for a wide range of spontaneous activities, like leisure, recreation, commerce-market, informal sport and dance, performance, ect. The rise of a new "cultural 
public space" in China, that has been described as "a space intermediate between state and society in which both participated" (Huang 1993: 224) offered the opportunity to look at the social context for the physical development and design of public spaces, a context in which the public sphere can be experienced and performed by citizens.

More recently, in Chinese cities the market economic reform has impacted on Chinese society, by the infusion of the private realm to the universal public realm, typical of the planned economic era, at all dimensions of space production. These new processes transformed public spaces but they did not produce an improvement of space, that in several cases even deteriorated (Miao 2011).

Against this backdrop, this work add resses the role of public space in improving people welfare and wellbeing in cities. It discusses the relationship between design, actions, and policies aimed to achieve this goal, in Chinese cities, with an eye to Shanghai, and specifically to Cao Yang New village (Fig. 1). Cao Yang New Village is one of the first urban development planned for workers in Shanghai, China, designed and built during the Fifties of the past century, just few years later Mao Zedong proclaimed the establishment of the People's Republic of China, on October 1, 1949.

Our work on Cao Yang New Village has been developed in the attempt to find answers to this kind of questions: how can we secure the citizens possibility to live their daily life in a network of collective spaces that are comfortable, sure and safe? How is it possible to or-

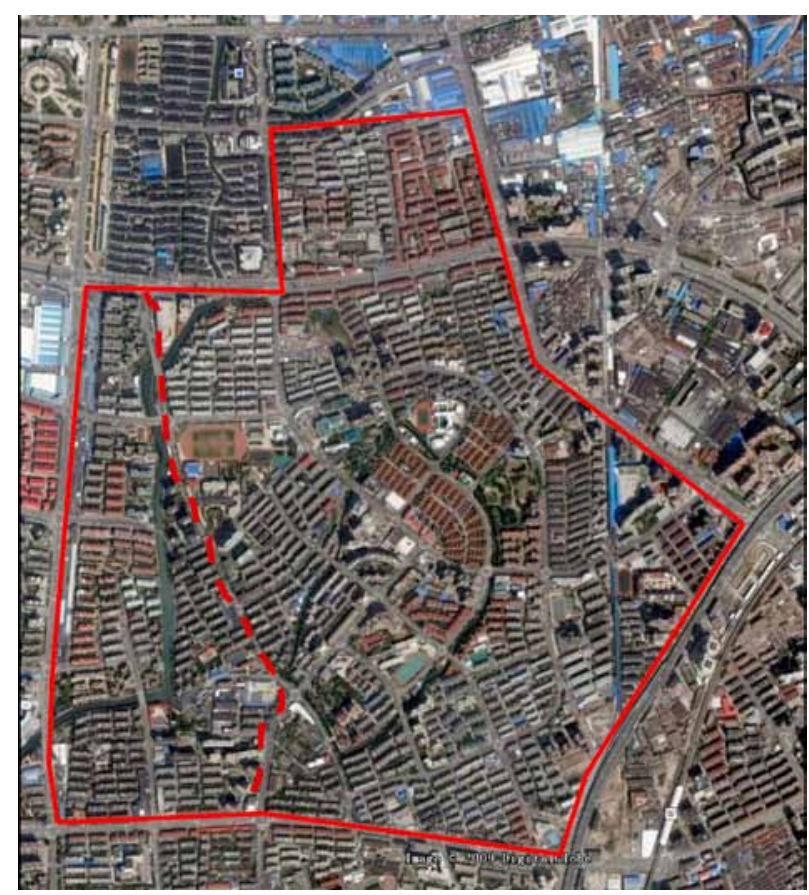

Fig. 1. Cao Yang in 2015 (Elaborated by the authors) ganise such network of collective spaces? Which ideas and tools are useful in designing appropriate strategies to increase liveability and improve social exchange?

This paper addresses these issues and it discusses how the improvement of the quality of the collective and the public spaces can positively affect the citizen wellbeing and the city welfare. After a brief discussion about how the role of the collective and the public spaces can secure a better quality of life, we then examine the specific case of Cao Yang New Village. We look at this neighbourhood through the lens offered by the experience and the representations of two well known pedestrian tissues, in the old city center of Venice and Rome, in Italy. We then present the main physical and socio-economic features of Cao Yang New Village, and we describe the variety of facilities and public open spaces, today scattered and fragmented in the Village. This analysis is then used to show how, by more dense connections among these spaces, it is possible to create the conditions for an improvement of quality of life of the people living in the Village.

We conclude that, by designing appropriate interventions for the enhancement of the connectivity and the porosity of this neighbourhood, we ease accessibility for citizens, especially for children, mothers, elderly, and people with disabilities, allowing them to get to schools, parks, sport facilities, public offices, and other collective spaces, therefore improving their wellbeing and the livability of the city. Our work suggests that a similar approach should be included in the agenda of many cities in China, thus contributing to the realization of the Chinese New Urbanisation Plan 2014-2020, which aims at a more sustainable growth, improved people's living conditions, and clearer cultural identity in cities.

\section{Public space and livable city}

Most cities, not only in the developed world, after the booming urbanization and the rapid population growth, are now facing two very important challenges that will change the composition of city' users, namely, the populations ageing and the lower demography, with the consequent changes in the family size and structure. Beyond, and adding to the environmental crisis, cities now face new population dynamics that will affect public spaces uses.

A people centered vision of the urban life stresses the importance of the wellbeing of the city inhabitants and users, thus proposing a new image of the contemporary city, where GDP ceases to be the rod to measure social and economic goals. Everyday life quality is interwoven with places in the physical city: places where we live impact on the quality of our lives, and in return, 
our lives contribute to making our own community a better place (Carmona et al. 2003; Crawford 1999; Munarin, Tosi 2014).

By understanding how people are able to achieve higher well-being, by creating new spaces and new opportunities to use them, we can identify those policies that can empower communities to act for this goal. This perspective is useful to shed new light on the human settling phenomena, infusing the idea that the urban quality is associated with urban dwellers wellbeing and accordingly collective spaces matters more than individual buildings.

In fact, in recent years, mainly through continuous experimentation with the contemporary city, one question emerges among the others: how the city and its various spatial articulations contribute (or fail to contribute) to the well-being of its inhabitants or, to put it differently, in which ways the complex set of actions designed to ensure greater well-being for different populations has contributed to build the contemporary city, both physically and in terms of facilities and spaces, and in term of urban quality of life (Hou 2010; Munarin, Tosi 2011). Within this approach, public spaces play a fundamental role. Both cultural and historic context make it difficult to describe and define what urban public spaces are; but there are also other reasons, like the interdisciplinary nature of the notion of urban public space. Different disciplines focus on various aspects: architects look at function and form, sociologists at interpersonal relations, economists at utility, value and principles of providing public space as a public good, philosopher at the public sphere, legal scholar at legal forms, including public property, public domain and the commons, and so on (Polko 2012).

Polko (2012), in his work on urban public space, by surveying a variety of studies, in various disciplines, outlines some specific characteristics and functions of public spaces which include: free access, public functions, facilitating direct social contacts and networks, collective activity, leisure time activity, strategic importance for local communities, offering different products for residents and visitors. Public space is ubiquitous in cities and it dialogues with private space.

Urban agglomeration has been historically organized around public spaces and streets (and intersections, assuming various forms), and in villages, towns, and cities, streets serve three main purposes: mobility, commerce and social interaction. Streets, roads, paths, passes are all public space, but they also aggregate around them more public space, serving several social and economic functions, such as residency, services, economic activities, leisure, and so on (Hall 2012; Ehrenfeucht, Loukaitou-Sideris 2009).
Urban life assigns them an extended multi-functionality, being links and places with commercial, economic, civic, ceremonial, political, cultural and social values. In this work, to analyse and interpret the idea of urban public space, we think there is no better place to think of than streets' space (in our case streets are also the pedestrian areas and pathways, as well as the paths along the river), the plentiful and visible parts of the urban commons.

In 2013 UN - Habitat published "Streets as public spaces and drivers of urban prosperity" where a first assessment of the contribution of streets on the prosperity of cities is offered (U.N. Habitat 2013). The City Prosperity Index (CPI) recently introduces a specific element of urban form, street connectivity: by having a look at this recent report, we see that Shanghai (and Beijing) range around 0.7 in the city prosperity index, while when this index is above 0.8 (maximum 1) cities do well in all components of prosperity, and prominently in street connectivity.

Looking at the city of Shanghai, we can say that the city is widely experiencing the tensions connecting economic growth, spatial organization and citizen wellbeing. It is one of China's most populous city and the largest city in the entire world; Shanghai's population in 2013 is estimated at 23.9 millions, and according to the 2010 Census, Shanghai's population was $89.3 \%$ (20.6 millions) urban and 10.7\% (2.5 millions) rural (Wang 2015).

More than 39\% of Shanghai's residents are longterm migrants, a number that has tripled in ten years and almost $80 \%$ of them are from rural areas. They have made up the largest percentage of the city's growth, as Shanghai's natural growth rate has been negative since 1993 because of low fertility rates. Moreover Shanghai has one of the highest life expectancies in the world, and the highest in mainland China, at 82.13 years. Some estimate that in China, by 2050 as much as $25 \%$ of the population (about 400 million people) might be over 60 years old, many of them living alone in isolated situations experiencing loneliness (Weiping, Gaubatz 2013).

According to this data, Shanghai, like other Chinese cities, during the last decades and in the near future will face a growing amount of people with more leisure time seeking for public urban spaces where to interact.

Despite that several parks today provide formal spaces for recreation, and community interactions, overall the urban fabric does not provide the quality of spaces that may really support the wellbeing of the residents. People in Shanghai continuously invent new public spaces, and places like sidewalks, underneath overpasses, sometimes parking lots are used for band 
rehearsal and performances, singing clubs, dance activities and storytelling (Xiangning et al. 2014). The hierarchical network of streets in many cases provides accessibility (even though with congestion) but it could deliver more, in terms of offering public spaces for a better city life.

Shanghaies, and Chinese citizens more generally, today are looking for an easier and less tiring way to move into the city. Instead of vehicular traffic, people want to reach public facilities by pedestrian and cycling paths, involving daily direct contact with other people, demanding a city more accessible and comfortable.

Recent studies have compared the connectivity of Chinese cities with other European and extra EU cities: the dimension of urban blocks in newly planned expansion zones of Chinese cities (Shanghai is an outstanding example in some areas) typically range from 400 to over 800 meters a side. This size, if compared with blocks in Tokyo that average 50 meters a side, or blocks in Paris and London, that average 120 meters a side, seems very huge. These superblocks are usually not divided into smaller plots, and this implies a small range of connectivity, a small number of intersections, and an environment that is not pedestrian friendly. Superblocks create a strong discontinuity, lack of complexity, and the differentiation of urban public places: less small plazas, pedestrian or cycle path, and places for citizens interactions. Sometime, in Chinese cities, the superblocks together with the high speed arterial roads acts as impassable barriers within the city, reducing the connectivity between neighbourhoods, as people are forced to walk more 500-700 meters to cross an 80 meter wide road (World Bank 2014). Consistently, they stop walking.

It is well known that the weakness in the road networks has negative impacts on walking and bicycling. In the absence of a good network of small roads, pedestrian and cyclist have no choice but to use public or mostly private transport (Newman et al. 2009).

In Chinese cities, bicycle use was highest and accounted for $50 \%$ or more of all trips by the end of the twentieth century, falling to less than $20 \%$ in the last decades. However, in Shanghai the trend is not so negative and the $35 \%$ of all trips are made by bicycles $(25 \%)$ or by foot (10\%) (Baeumler et al. 2012). The electric bicycles are growing in importance, and it is estimated that in Shanghai some $70 \%$ out of the traffic in bicycle lanes is accounted for by e-bikes (Pooley 2013).

Against this backdrop, planning and policies aiming to improve city welfare and citizens wellbeing should works to forge and to revitalize public spaces and they need to consider that streets, roads, paths, passes are the nexus of much of the multi-functionality in cities. Around them, the various nested interests which correlate with the various city' functions offer support to create consensus amongst the disparate interests, thus helping in creating a space where mobility is also balanced with place making, and local commerce with active living of people.

To achieve these goals, the enhancement of the connectivity and the porosity of the cities, as well as the increment of the number of intersections, and the presence of narrow streets and paths, running from block to block, with walking and cycling paths, are among the most appropriate actions for producing more and more free open spaces, available for social interaction, and sometimes also for informal and ephemeral activities (dance, open air gym, Thai chi, ground calligraphy are emerging activities looking for such kind of public spaces).

To demonstrate the strength of our arguments, we now turn to the specific site of Cao Yang New Village, to show how, the efforts to transform the city in order to generate more public places can be a sources of revitalization, new revenues, generated by the new use of high-value existing urban land, and an overall improvement of citizens wellbeing.

\section{The case study: Cao Yang New Village}

The physical and socio-economic features of Cao Yang New Village, its history and the quite rich and abundant facilities and public open spaces in the area make this neighborhood an ideal place to investigate the possibility of using diffused, small and inexpensive design interventions with the goal of improving the quality of life of the local citizens. In fall 2014, an International Workshop, jointly organized by IUAV University of Venice and the College of Architecture and Urban Planning, Tongji University, was held on the site with master students from both Universities, and the results of this work has been presented at the Shanghai West Bund Biennale in 2015, for the Shanghai Urban Space Art Season. Through this work, instead of using only official statistical data or abstract academic concepts, we attempted to provide an overview and several suggestions on the urban public spaces of Cao Yang New village, primarily from the direct experience of them.

Cao Yang New village is a Shanghai neighborhood located in northwest Shanghai, 8.4 kilometers from the city center. It is north of Zhongshan Road North, and to the west of Caoyang Road. Although it was on the outskirts of Shanghai at that time of its first development, it was not far from the factory districts of Changning, Putuo and Zhabei. In September 1951, the first phase of the village project started, and it was completed in May 1952. Today it is known as the first 
Cao Yang New Village. The 48 buildings spread over 13.3 hectares and 1,002 families quickly moved in to the first socialist workers' village in China. In 1952, the Shanghai Municipal Government began building 21,830 similar apartment blocks throughout the city to accommodate the rapidly increasing population. They were known as "The 20,000 Households" (Weiqiang 2014). The village hosts nowadays 100,000 inhabitants, of which $30 \%$ rural-urban migrants and $20 \%$ of ageing people, and its population has increased overtime, since its early foundation, by adding up new compounds within the boundaries of the neighborhood. During the past five decade also the social and demographic composition of the population has changed, given the radical economic transformation of the economic base in Shanghai. Yet, many of the old inhabitants or families are still there. Since the end of the 1980s, several community participation projects in China have been implemented: one of them was carried out recently also in Cao Yang Workers' Village, and this participatory process seems to have fostered local governance to make significant breakthroughs (Kern, Bolay 2014; Matthey 2011).

In term of design, the historical project of Cao Yang Village is based on the concept of American "neighborhood unit" (Perry 1929) for what concerns the open spaces, and on the Soviet residential unit for what concerns the residential buildings (Kopp 1970); the village is organized in several units, each one closed by fences and gates (Fig. 2).

The overall planned area of Cao Yang new village was 94.63 hectares, with a radius of about 0.6 kilomet-

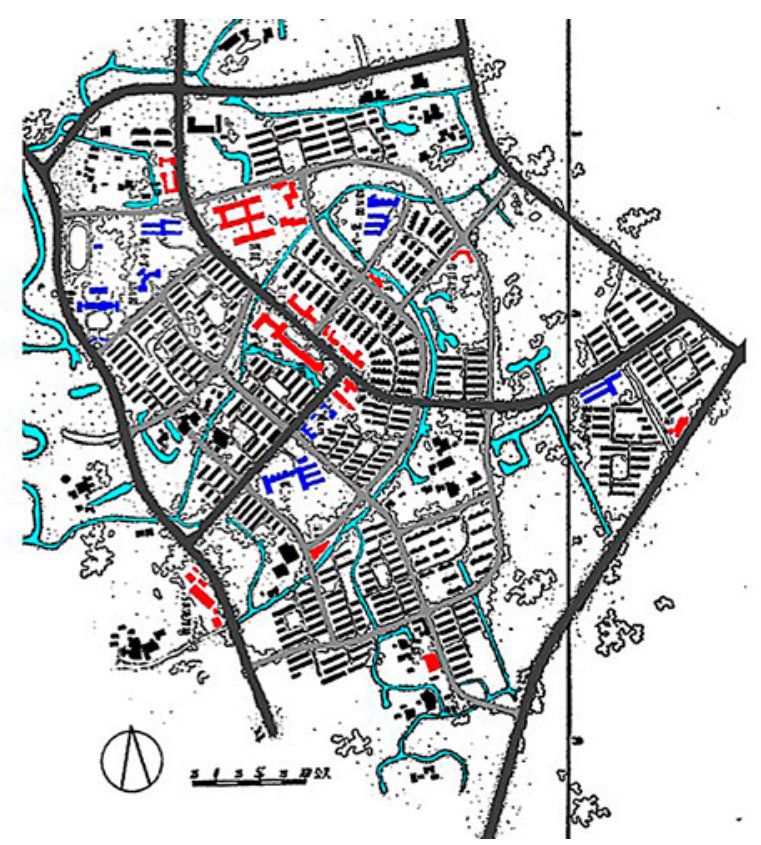

Fig. 2. Plan of Cao Yang New Village in the Fifties (Elaborated by the authors) ers. It takes seven or eight minutes, to walk from the center to its edge. In addition, all public facilities such as cooperatives, post office, banks and museums were planned to be set in the geometric center. Both the food market and the branch of the Cooperatives were planned to be spread within the edge of the village, so that it was convenient for residents to buy daily necessities in the vicinity.

One of the most interesting features of the 1951's plan are the uniform distribution of elementary schools and kindergartens, located no more than 10 minutes away from residency, and the preservation of the existing natural elements within the site, two small rivers and several scattered creeks. The original plan for Cao Yang new village adopted a free-curved non-geometric road structure, and today the tree lined curve streets is still an important character of the village.

Another important feature is the character of open collective spaces in Cao Yang, where the many walls and fences do not limit the village in itself, but its original residential units, called "danwei" and today corresponding to the "residential communities".

The initial organizational structure of Cao Yang New Village, its initial planning and construction, was posing a basic pattern in social population reproduction and residents' daily life. With comprehensive and qualified organization, the space system and the public service system still reflects a comprehensive integrated form, in terms of content, scale, shape, and landscape. In addition, it meant to offer an ideal life of Realistic Utopia, with a lifestyles organization for the working class, even though real life conditions were harsh. In fact, it served the working class well with a full range of living arrangements, a beautiful environment of life scenes, and convenient and cheap socialization of public service.

From the management point of view, public housing was mainly organized into two types: one was run by real estate department, with unified investment and construction; the other was run and owned by the factories, directly investing in housings and construction. The whole project consisted of a total construction area of 195,151 square meters, of which more than 150,000 square meters were devoted to services. At the time, most residents were workers and cadres, working the surrounding factories and in social public services. Cao Yang was a demonstration site for a model of living a collective life and achievement of a collective welfare.

Through time, the village more and more was organized and enclosed by fences and gates. Today, everything beyond such walls and fences is public space: the streets, the pedestrian pathways, the neighborhood markets, the paths along the river, the 
public parks. These spaces allow people to do many different activities: meet each other, go for shopping, playing and practicing gym, dancing, play chess, and so on. On the contrary, everything inside the residential units is only semi-public, mostly dedicated and used by people living there, and yet, at the same time, easily accessible by anyone walking through the entrance gates (Chen 2011).

In these protected areas you can breathe a village, or small town, air and live accordingly, even though some of these units are composed of buildings more than ten stories high. Everywhere there is room for physical activities, to sit and talk, to park the car and be together.

The physical and emotional experience of walking in Cao Yang is worth mentioning: it is a pleasant place for all the senses, busy and quite at the same time, varied and simple, surprising and normal, in one word attractive. Then, for people visiting Cao Yang from Venice, who every day experience similar conditions, the mind immediately calls for a comparison, for an effort of understanding the differences about the use of public spaces in the two contexts, thus helping us to highlights possible strategies for addressing a better use of Cao Yang spaces, creating a new sense of community (Shane 2015).

Venice, the "city on water" par excellence, poses interesting questions from the perspective of public space. The impossibility for traditional modes of urban transport has helped developing a city on a human scale, entirely pedestrian, as everybody knows. In Venice public areas are organized in Campi (the local plazas) of different shapes and dimensions, and the "calli" (the main pedestrian paths) are also seen as the privileged places for both social and commercial exchange. In a city like Venice, privacy is difficult to achieve and you are always exposed to public life; sometimes, you feel the need to find refuge and solitude within some locations, small or larger, far from busy crowd and life. A walk along the "calli" (narrow paved paths) make the visitor think that the city is dense in buildings and habitants; on the contrary, behind the wall that limit the calli you might often find large or small relaxing gardens. These courtyards and "hidden" gardens are one of the treasures of Venice, places where you can escape the public and find yourself. These spaces in many cases are not strictly private, such as home garden, and everyone can access them; yet to access them you need to know where they are, or just get to them by chance, by using the city as a pedestrian.

\section{What about Cao Yang urban public spaces and walking paths?}

The village maintains the original subdivision of the neighborhood into several residential units, each of them endowed with its own varied and composed small open spaces and recreation facilities, actively used by local people. Each residential unit is fenced and accessible by one or more gates, some of them controlled by a porter: individuals and vehicles, including bikes use these gates many times every day. Residential units are open and close at the same time, and around we found connecting public spaces such as schools, every 500 to 800 meters and streets. The larger green spaces are mainly distributed along a small water channel, shaping a sort of green belt, once fully accessible and now privatized, given the construction of new buildings (Fig. 3).

These wounds seriously affect the continuity of the network of the open spaces. Moreover, large areas of the public space are made of commercial spaces, distributed along the main roads that are all tree-lined and with a pedestrian path. Bikes are ubiquitous but only few roads have bike path.

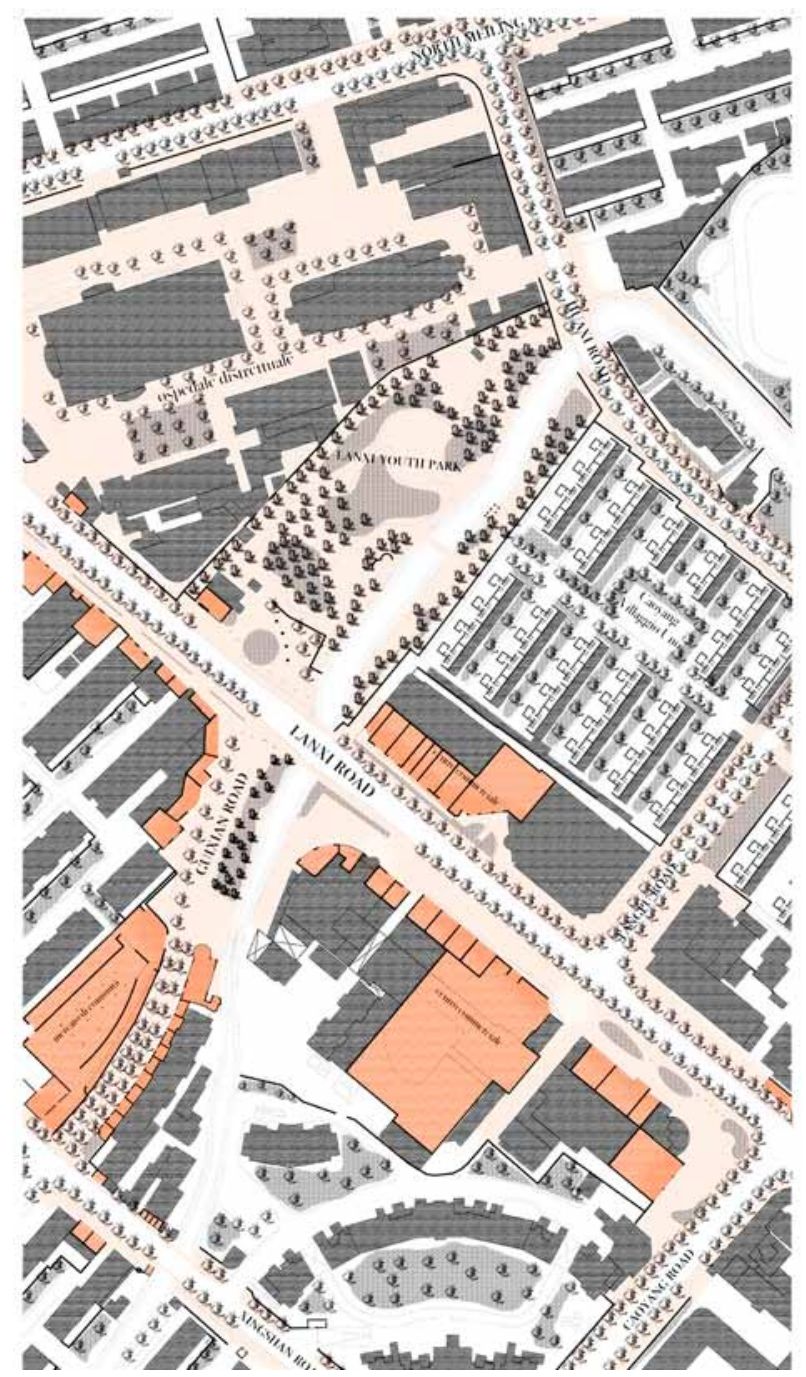

Fig. 3. A fragment of Cao Yang represented in the style of Nolli Map (Elaborated by the authors) 
In conclusion, the neighborhood is quite well equipped of public spaces but what is missing is a network of easy links among the different spaces and facilities; lacking such links, it is not that easy for people to move around and fully enjoy the potentials of the places.

The many elderly residents that play chess and dance in the parks, and the younger that play gym in the open air facilities, or that use the many street food shops, only shares little in the public space and they do not have the possibility to easily walk and move among those spaces. It's like an archipelago of gated collective spaces, with just a few relationships among them and under this perspective, by comparing Cao Yang New village and the Italian historical pedestrian cities, like Venice or Rome, the importance of connectivity between various places and facilities comes out very neat.

\section{Design for accessibility and porosity: how to make Cao Yang a better place to live in}

In 1748 , the cartographer and architect Giovanni Battista Nolli published the first detailed modern map of the city of Rome, commissioned by Pope Benedict XIV (Verstegen, Ceen 2013). This map is quite original since it represents not only roads, squares and open spaces around the city, but also it shows all the public or semi-public areas inside the buildings, such as churches, convents, cloisters, porticoes, covered markets, and Palace Gardens. Such innovative representation makes possible to understand today how and where public life was unrolling in Rome at that time, revealing its porosity, namely the way in which the urban spaces were suited to the needs and activities of its inhabitants. Nolli's work is stimulating and it suggests us to apply his vision and representation to a small portion of Cao Yang, to make an experiment and to read the Cao Yang urban structure in terms of the lens used by Nolli in Rome, many years ago. Obviously in Cao Yang you won't find the cloisters and churches, but markets, malls and shops, and other structures. This experiment shows us that the public space in Cao Yang, par excellence, seems made up by the roads, situated in front of these various facilities and service (Fig. 4).

Nolli suggests us to give visibility also to all the other possible spaces, representing the spatial support for the urban life, and as we described, the public or collective spaces in Cao Yang are also within the residential units and buildings. Originally, the earliest houses (built in 1952) had bathrooms and kitchens on the ground floor, to be used and shared by two or three family groups, in each portion of the building, and these spaces need consideration.

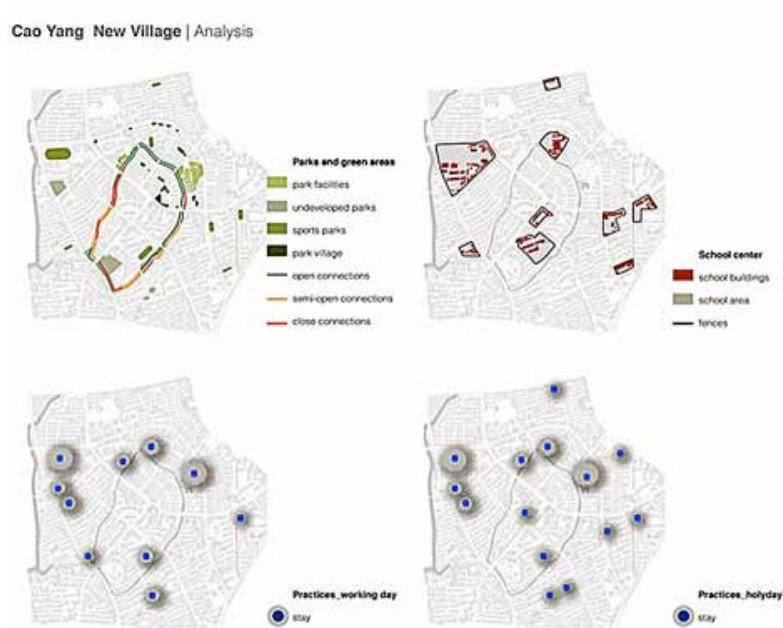

Fig. 4. Analysis of Cao Yang: park and green areas, school center, practices (Elaborated by the authors)

Putting together Nolli's vision and our knowledge of Cao Yang new village, we are able to develop a strategy to add value to its spaces, to the multiple shared practices of urban communing, and to improve the community wellbeing, making the village more inclusive (Shannon et at. 2014).

The strategy is twofold: the first one is to develop porosity, the second one is to work on accessibility.

Porosity implies addressing the way by which new inhabitants and new users, together with their collective and public activities, may percolate through the existing city, and thus, by transforming it, they may enhance the livability of the spaces and the well being of the involved citizens (Secchi, Viganò 2009).

The way we approached the necessity to upgrade Cao Yang livability is to address the relationship between interior and exterior in urban space, i.e., using playgrounds and patios, gardens, sports facilities at open air, street food areas, etc., as physical and social tools for improving connections. The design aims to create infrastructures and facilities for conviviality and sociability; it serves the purpose of securing the quality of life and work in the city, of maintaining a sufficient amount of open space in high density areas, of reusing vacant and underused areas and empty buildings, of creating a micro fabric of links for bikes and pedestrians.

Accessibility implies addressing the way by which the lower network, made of tree-lined streets, pedestrian and cycle paths may absorb the movements in the city, like a sponge. Such varied and composed system of connections, in place in Cao Yang, is as important as the principal road infrastructure, since it constitutes the main connecting structure for the village, being a fundamental support for daily activities. Such system, with its great capacity to increase connectivity, 


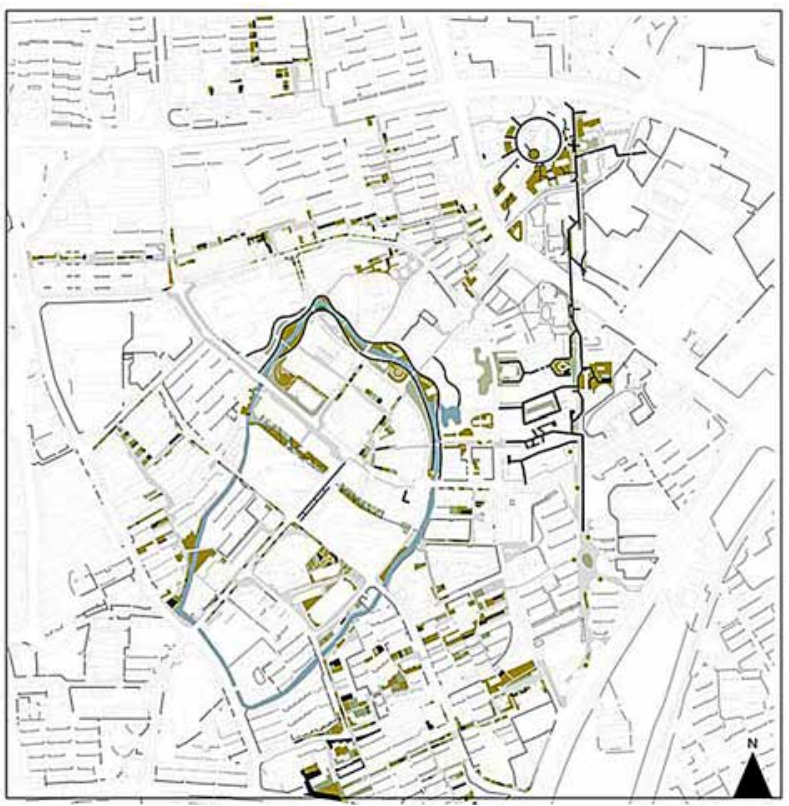

Fig. 5. Masterplan for Cao Yang (Elaborated by the authors)

can play a structural role in improving the quality of the use of the different, various and diffused available spaces, in the village: for example, the civic centers, the commercial streets, the areas around the metro station (U.N. Habitat 2013).

The concepts of porosity and accessibility have been used in many urban models (space syntax, fractal analysis, integral urbanism) because of their theoretical and practical contribution; we use them to show how open spaces and how we use them can contribute to a more resilient and inclusive city. The results of our design exploration are shown in the Figure 5.

The table describes our interventions in Cao Yang for the purpose of revitalizing existing public spaces, by proposing some new ways of living the village. The design expands existing connections, it gives them a clearer recognition, it makes Cao Yang suitable for pedestrian and bicycle users, and it reinforces the links to all public transports. The overall accessibility and porosity is highly improved.

With a lot of new pedestrian routes and redeveloped spaces within communities, Cao Yang will be a place in which people can easily meet, trade, have fun, walk, play, and relax. All these simple urban practices can enjoy the possibility to revive in today's forgotten or unused places in the village. Our goals, to improve the urban fabric and also the social community in the public spaces, are achieved and the village may experience its natural unity, lost over the years.

These results, moving up to an higher scale, indicates that these two combined strategies could help the whole city, even a megacity like Shanghai, to invent new ways of living together, enhancing the welfare and the wellbeing of its inhabitants.

\section{Conclusions}

Chinese cities, including Shanghai, are now struggling to improve urban functions, operational efficiency, and the quality of urban life. Chinese Local and Central Governments, facing a continuous wave of urbanization, for many decades ahead, strive to introduce innovation in design practices. While new physical constructions in existing and new cities will be necessary, also the upgrading of the existing urban structures and public spaces is deeply needed. Our research and design is an example of the role of policies and design for improving connectivity and accessibility with the aim of improving the network of open spaces, of education and healthcare facilities, to achieve livability in the city.

Our work shows how the enhancement of the quality of collective and public spaces can be feasible, also by working at a micro scale, by detailed design interventions, pursuing higher connectivity and the porosity of a single neighborhood in the city. These interventions, sometimes easy and cheap, give rise to an easier accessibility for all categories of citizens, allowing them to get to the services they need, to invent new ways of living the space within their reach, thus improving their wellbeing. Our demonstration site, Cao Yang New Village, one of the first urban development planned for workers in Shanghai, China, designed and built during the Fifties of the past century, and now home for more 100,000 people, has offered us the possibility to showcase the theoretical and practical "potential" of conjugating the notion of public and that one of urban space. Our research design not only increases the wellbeing of Cao Yang New Village people, but also set up the base for a new attractiveness of this neighborhood for new dwellers, for new middle class families with children, for the elder people now rapidly increasing in Shanghai, preserving social variety and opening to new economic businesses, thus avoiding the fall of the neighborhood in a process of gentrification.

\section{References}

Baeumler, A; Ijasz-Vasquez, E; Mehndiratta, S. (Eds). 2012. Sustainable low carbon city development in China. The World Bank. Washington.

Carmona, M; Heath, T; Oc, T; Tiesdell, S. 2003. Public Places. Urban Spaces. Burlington, MA: Architectural Press.

Chen, C. 2011. Grandma's world: mapping dancers in Beijing, in Proceedings of the 42nd Annual Conference of the Environmental Design Research Association, 25-28 May 2011, Chicagi, Illinois.

Crawford, M. 1999. Blurring the boundaries: public space and private life, in J. L. Chase, M. Crawford, J. Kaliski (Eds). Everyday Urbanism. New York: The Monacelli Press. 
Ehrenfeucht, R; Loukaitou-Sideris, A. 2009. Sidewalks: conflict and negotiation over public space. Cambridge, MA: MIT Press.

Gaubatz, P. 2008. New Public Spaces in Urban China, China Perspective 4: 72-83.

Habermas, J. 1989. The structural transformation of the public sphere. Cambridge, MA: MIT Press.

Hall, S. 2012. City, street and citizen. The measure of the ordinary. New York, London: Routledge.

Hou, J. 2010. Insurgent public space: guerrilla urbanism and the remaking of contemporary cities. New York, London: Routledge.

Huang, P. C. C. 1993. Public sphere and "civil society" in China? The Third Realm between State and Society, Modern China 19(2): 216-240. https://doi.org/10.1177/009770049301900207

Kern, A-L; Bolay, J. C. 2014. Participatory processes in urban planning projects in China: the example of Caoyang Village, Shanghai, in J.-C. Bolay, S. Hostettler, E. Hazboun (Eds.). Technologies for Sustainable Development. Berlin: Springer.

Kopp, A. 1970. Town and revolution. Soviet architecture and city planning 1917-35. New York, NY: George Braziller.

Low, S.; Smith, N. 2006. The politics of public space. New York, London: Routledge.

Matthey, A. 2011. Rénovation urbaine à Shanghai. Nouveaux villages ouvriers de Caoyang. Theoretical work. Master: Ecole Polytechnique Fédérale de Lausanne (EPFL).

Miao, P. 2011. Brave New City: three problems in Chinese urban public space since the 1980s, Journal of Urban Design 16(2): 179-207. https://doi.org/10.1080/13574809.2011.548980

Munarin, S.; Tosi, M. C. 2011. Spazi del welfare. Esperienze, luoghi, pratiche. Macerata: Quodlibet.

Munarin, S.; Tosi, M. C. 2014. Welfare Spaces. On the role of welfare state policies in the construction of the contemporary city. Trento-Barcelona: Listlab.

Newman, P.; Beatley, T.; Boyer, H. 2009. Resilient cities, responding to peak oil and climate change. Washington: Island Press.

Perry, C. 1929. The neighborhood unit. Regional Survey of New York and Its Environs. Vol VII. New York, NY: Russel Sage Foundation.

Pooley, C. 2013. Promoting walking and cycling. Bristol: Policy Press.

Polko, A. 2012. Urban public spaces - from economics to management, in K. Heffner A. Polko, (Eds.) Urban public spaces - economics and management perspectives, Studia Regionalia. 34. [online], [cited 20 November 2015]. Available from Internet: https://www.academia.edu/5485636/Urban_ Public_Spaces_-_from_Economics_to_Management_A._ Polko

Secchi, B; Viganò, P. 2009. Antwerp. Territory of a new modernity. Amsterdam: SUN.

Shane, D. G. 2015. Chinese rapid urbanization and the Metacity, in W. Ding, A. Graafland, A. Lu (Eds.). Cities in transition. power, environment, society. Rotterdam: nai010 publishers.

Shannon, K.; De Meulder, B.; Yanliu, L. (Eds.). 2014. Village in the city; Asian variations of urbanisms of inclusion. Chicago: University of Chicago Press.

U.N. Habitat 2013. Streets as public spaces and drivers of urban prosperity. Nairobi UN Human Settlements Programme.
Verstegen, I.; Ceen, A. 2013. Giambattista Nolli and Rome. Mapping the City before and after the Pianta Grande. Roma: Studium Urbis Center.

Weiqiang, W. 2014. Personal Interview.

Wang, G. 2015. The state of China' cities. UNHABITAT. Beijing: China City Press.

Weiping, D.; Gaubatz, P. 2013. The chinese city. New York, NY: Routledge.

West Bund Biennale 2015. The Shanghai urban space art season [online], [cited 1 November 2015]. Available from Internet: http://www.susas.com.cn/en/theme/1/act/14

World Bank; Development Research Center of the State Council, the People's Republic of China. 2014. Urban China: toward efficient, inclusive, and sustainable urbanization. Washington, DC: World Bank.

Xiangning, L.; Danfeng, L.; Jawei, J. 2014. Made in Shanghai. Shanghai: Tongji University Press.

\section{MARIA CHIARA TOSI}

Maria Chiara Tosi, teaches Urban Design in the University IUAV of Venice. Visiting Researcher at UC Berkeley (1995), PhD in Urbanism at La Sapienza-Rome (1996), Associate Professor at IUAV University of Venice (since 2006) where she is also member of the faculty board of the $\mathrm{PhD}$ in Urbanism. She is Vice President of VEGA Venice Gateway for Science and Technology (Since 2015), and in 2016 she has been selected as expert for the Research Foundation Flanders FWO. Her recent books include: Welfare Spaces. On the Role of Welfare State Policies in the Construction of the Contemporary City (2014), and Toward an Atlas of European Delta Landscape (2014).

\section{MARGHERITA E. TURVANI}

Margherita Emma Turvani, teaches Political Economy in the University IUAV of Venice and in Venice International University. She has an outstanding record of study and research in the field of Sustainable Development and Economics, Regional and Urban Economics, and she has a vast experience in multidisciplinary investigation and collaboration in research with academicians and experts in various fields, bridging Political economy with environmental science, information technologies, physical planning and policies and urban studies as well.

\section{STEFANO MUNARIN}

Stefano Munarin, teaches Urbanism and Urban Design in the University IUAV of Venice. Visiting Researcher at UC Berkeley (1995), PhD in Urbanism at University IUAV of Venice (1996), Researcher at University of Catania (2004-2010), Associate Professor at IUAV University of Venice (since 2010) where he is also member of the faculty board of the $\mathrm{PhD}$ in Urbanism. $\mathrm{He}$ is on the Board of Italian Urban Planner Society and Mandatory of the Rector at IUAV for the sport activities. His recent books include: Welfare Spaces. On the Role of Welfare State Policies in the Construction of the Contemporary City (2014), and Italia 1945-2045. Urbanistica prima e dopo (2016). 